\title{
Teaching research of Immersion Computational Thinking in C++ Instruction
}

\author{
Zhao Ni \\ Xi'an Technological University \\ Computer Science and Engineering College \\ Xi'an, China \\ e-mail:651124115@qq.com
}

\begin{abstract}
Computational thinking is a kind of universal thinking method. Design of $\mathrm{C}++$ Programs is an important subject of basic computer teaching for engineering specialty of higher education institutions. Aiming at the requirement that high education institutions shall cultivate high quality innovative talents, it puts forward the immersion computational thinking instruction system and the teaching guideline of three stages of teaching, three layers of experiment and three aspects of examination. Furthermore, it discusses the concept of overall and systematic immersion computation thinking and gradually better students' application capacity of computational thinking.
\end{abstract}

Keyword-Computational Thinking; Immersion Instruction Approach; Design of C++ Programs; Instruction System

\section{INTRODUCTION}

At present, it is recognized that experimental method, theoretical method and computational method are three scientific methods in natural science field. Correspondingly, three scientific methods as experimental thinking, theoretic thinking and computing thinking are formed. It is generally known that physical science may cultivate the experimental thinking characterized by observation and summarization of natural law, while mathematics may cultivate the theoretic thinking characterized by reasoning and deduction. In the long run, human civilization evolves with development of these two sciences. With the development of computer science, another thinking method characterized by design and structure becomes more popular in the science circles; this is computational thinking or structured thinking represented by computer science. In ancient times, man uses "fingers" to count and knotting to remember incidents. From "abacus" of ancient China to "adder" of mechanical computing apparatus of western countries, all these things show that computational thinking has emerges in human thinking in early period not the period that the computer emerges. It is the integral part of human thinking and the research on computational thinking has been done as integral part of the mathematical thinking for a long time. The emergence of computer strengthens the significance and action (Wang Feiyao, 2007). Therefore, it is necessary to innovate or cultivate innovative talents for the popularization of computer application, breaking away from prejudice of traditional teaching in today's information society. It can make students to think like computer scientist.

\section{ESSENCE OF COMPUTATIONAL THINKING}

In March 2006, Professor Jeannette M.Wing, Dean of Computer Department of Carnegie Mellon University published and defined Computational Thinking on Communication of the ACM, the authorized computer magazine, USA. She thinks that the computer thinking is to use fundamental concept of computer science for solution, system design and understanding of human being's behavior covering a series of thinking activities (Wing J M, 2006). She defines on the research paper that computer thinking is:

- Not programmable thinking but conceptual thinking;

- Not mechanical skill but fundamental skill;

- Not computer thinking but human being's thinking

- Not mathematical thinking but the thinking combining teaching and engineering.

- Not thinking of computer scientist but the thinking of all persons. 
Professor Jeannette M.Wing also thinks that computational thinking shall lie in analytic capacity beyond arithmetic, writing and reading. Like today's ubiquitous computing, computational thinking will be a basic skill of each person in future (Wing J M, 2008).

The essence of computation thinking is reasonable abstracting and high efficient arithmetic (Chen Guoliang, et al. 2011, Dong Rongsheng, et al. 2009). It is this capacity of structured thinking that shall be absolutely mastered by high quality innovative talents. It also is the purpose for engineering universities and colleges to set the course of $\mathrm{C}++$ programming language.

\section{HIERARCHICAL SYSTEM OF IMMERSION}

\section{COMPUTATIONAL THINKING TEACHING APPROACH}

Immersion teaching, originally, is an effective teaching mode in foreign language learning. It puts students into the second language environment in their whole or half of campus time. Teachers only use the second foreign language to communicate with students. $\mathrm{C}++$ Programming Language is a language of computer science, which has the similar cognition rules as human being's learning man's language. If the teacher "immerses" the concept of computational thinking in the whole teaching process, then the students may get rid of the shackle of imagery thinking formed for a long time and form the habit of using high efficient computational thinking to consider problems.

Comprehensively consider the knowledge system of $\mathrm{C}++$ Programming Language and the relationship with the computational thinking, the hierarchical system of Immersion Computational Thinking Teaching Approach is designed, integrating teaching, experiment and examining from the different angles such as scope of knowledge broadening, developing of learning hierarchy and time approaching. See Figure 1.

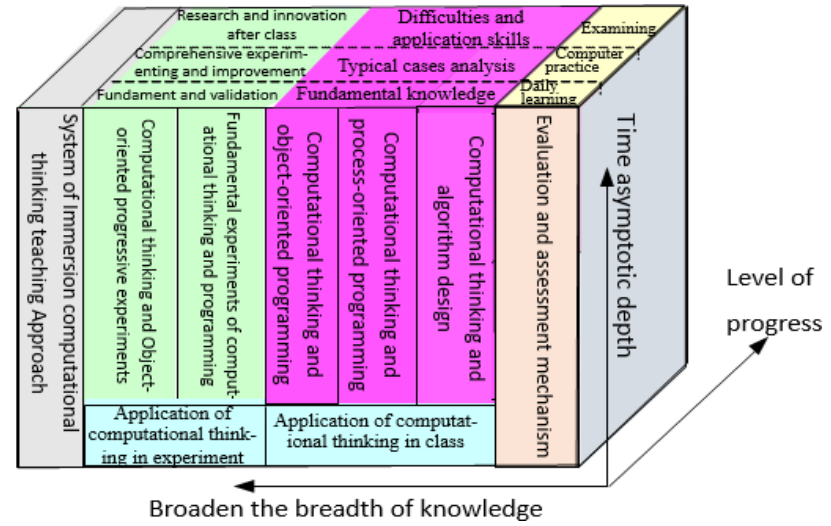

Figure 1. Hierarchical System of Immersion Computational Thinking

Teaching Approach

Furthermore, the guideline of "Three Teaching Stages, Three Experimenting Layers and Three Examining Aspects" is put forward during the teaching process. Namely:

- Three Teaching Stages: from the angle of learning layer, organize the teaching contents as three stages of fundamental knowledge explanation, typical cases analysis and difficulties and application skill. Through teachers' words and deeds, guide the student to form the habit of computational thinking gradually. The forming of the habit only is the good beginning while the computational thinking capacity for solving complex problems needs constant studying and more practice.

- Three Experimenting Layers: University and college education focuses on the quality of students and their skill improvement. That the school majoring science and technology subjects generally set the $\mathrm{C}++$ programming language is to cultivate students' programming skill. Therefore, according to the knowledge points, the supporting experiments are separated into three layers of fundament and validation, comprehensive experimenting and improvement, research and innovation after class. It immerses the computational thinking into these layers in order to practise the capacity of students to use computational thinking method to solve problems.

- Three Examining Aspects: change the examining method that uses writing test to define the mark, form the long-term examining mechanism of "daily learning + computer practice+ examining". Daily learning occupies $20 \%$ of mark (including $10 \%$ of daily attendance, class performance and learning attitude and $10 \%$ of after-class assignments), computer practice occupies $30 \%$ of mark and writing score only occupies $50 \%$ of mark. It is to encourage students to study initiatively and participate into the after-class research and innovative discussion, to check them from the learning process. The purpose is to let them have fun from learning. Such examining may reflect students' real 
learning level.

\section{DESIGN OF IMMERSION COMPUTATIONAL THINKING TEACHING}

It is conducive to cultivating students' computational thinking capacity from all aspects and more angles by applying three dimensional immersion computational thinking teaching into the learning and teaching. According to the extent of knowledge broadening, the application of computational thinking in class is separated into three parts: computational thinking and arithmetic design, computational thinking and process-oriented programming, computational thinking and object-oriented programming. Accordingly, experimental teaching is separated into two parts: fundamental experiments of computational thinking and programming, computational thinking and object-oriented progressive experiments. The following is to analyze how to introduce computational thinking into class teaching of arithmetic design.

Nikiklaus Wirth, the famous computer scientist put forward: program $=$ data structure + arithmetic. Here data structure refers to the description of data while arithmetic refers to the method and procedure to solving problems, it is soul of program. High efficient arithmetic is one of essences of computational thinking. Therefore, during the teaching of $\mathrm{C}++$ Programming Language, the principle of arithmetic priority is recommended. Namely, arithmetic is first, and then is the grammar and programming skills.

What is arithmetic? Arithmetic refers to the accurate complete description on solution to problems, a series of clear orders or procedures solving problems. It can obtain required output in given time after inputting according to some rules. Using computational method to solve practical problems, one shall know the effective decomposition of problems. So the computing result shall be obtained quickly. Commonly, a problem shall be solved with different methods or minds. It is the high efficient arithmetic that designing computing process can obtain accurate and reliable result in the shortest time.

Let students master the computational thinking capacity during the designing of arithmetic and make them know the application of reasonable abstracting. "Abstracting" refers to modeling and simulating on physical world and it explains the change of physical world to a kind of computing process; regard the research on physical property as a computing process. This is the process from concrete to commonness. For example, in the real world, we take trees, flowers and grass as a category called plant; take cat, dog as a category called animal; take you, me and him as a category called human being. Use the classifying thinking into computer world, then we have basic categories of datum (for example: Char type, integer type, floating point type etc.); take the "concept that everything in the world has its life" into computer world, then variable has its survival period and scope. Because the computer's storage space is limited, different type of data has its scope restriction.

Now, let's look at some examples in life: when you go to school, you may put necessary thing into your bag; do you think that this is pre-placing and buffer memory? When you lose these things, you may look for them along the road you have passed by. Do you think this is back step? When you are puzzled by adjustment of learning process, do you think this is the reflection of Darwin's Evolution Theory. You are absent-minded which line you shall line when you prepare to make payment in the supermarket, do you think this is the performance model of multi-servers system? Such examples are too numerous to mention one by one. All these show us one reason, that is, computer world is the abstract of real world. You upset when you study courses of computer, use you abstracting swing and you may find the prototype in the real world. The learning of computational thinking is to make student have fun in these two worlds of real world and abstracting world.

In the past, during the teaching of $\mathrm{C}++$ Programming Language, in the chapter "Arithmetic Design", more problems are explained, which make student think that computational thinking is mathematical thinking. Actually, computational thinking refers to the mind that uses computer technology to solve problems. It is different from the confirmation thinking in physics and logic thinking in mathematics and "structure", "structure" and "automation" is its core thinking. For example, some complex image is made of some simple graph according to some rules. The 
capacity of computational thinking is the capacity that can find the simple phenomenon and common principles from complex things.

When using computational thinking to solve problems, pay attention to separation of concerns (SOC). This like the story of "Carving up an Ox" given by Zhuangzi, an ancient thinker of China. Butcher cook Paoding can decompose the ox at ease because he is familiar with the bones of ox not the whole ox. This story tells us: give concern on the major part not the minor part. As for the application of computational thinking in arithmetic design in the course of programming design, it requires student know how to grasp the major part that can be realized through computer during analyzing problems, rational grasp the "links" of problems. This is the essence of separation of concerns.

The computational thinking also has other common methods of data reduction, embedding, transform, recursion, heuristic reasoning as well as the computing acceleration by using huge quantity of data etc. during the teaching, teacher does not teach the key points of computational thinking, but also guide students to find similar cases in life. Knowledge comes from life and goes back to life, the thinking habit will be cultivated in such comparison.

\section{DISCUSSION}

The purpose of immersion computational thinking teaching: based on the foundation, strengthening the practice, cultivating students' computational thinking and applying innovative capacity gradually. During the teaching and learning, the teaching content shall be standardized and good thinking habit shall be cultivated. Meanwhile, guide emphatically, advocate the diversities of arithmetic, encourage students to participate into problem discussions, broaden the capacity of computational thinking. Therefore, teacher shall give concerns on the following during the teaching process:
1) Straightening the cultivation of student on problem abstracting capacity;

2) Paying attention to cultivating students' capacity of computational thinking;

3) Improving student's computer practice capacity;

4) Cultivating students' overall outlook and systematic outlook;

5) Studying the balance of grittiness and compromise;

6) Stressing the team cooperation spirits

7) Practicing organizing capacity and expressing capacity.

\section{CONCLUSION}

$\mathrm{C}++$ Programming Language is an important subject in fundamental computer teaching in engineering major of higher educational institutions. It plays an important role in cultivation of students' quality and innovative capacity. Computational thinking is an effective thinking method to solve problems and it also is a basic skill that shall be mastered by new century's students (Mou Qin, Tan Liang, 2011). Immersion computational thinking teaching method is easier to immerse and strengthen computation thinking capacity in programming design teaching and it can cultivate high quality innovative talents. Each of us, not only all computer scientists, shall actively participates into the studying and operation actively.

\section{REFERENCES}

[1] Wang Feiyao (2007), From Computational Thinking to Computational Culture, J. Communications of China Computer Federation. 11, 3, 72-76

[2] Wing J M(2006), Computational Thinking, J. Communications of the ACM. 49, 3, 33-35

[3] Wing J M (2008), Computational Thinking and Thinking About Computing, J. Philosophical Transactions of the Royal Society. 366 , 3717-3725

[4] Chen Guoliang, Dong Rongsheng(2011), Computational Thinking and College Computer Fundamental Education, J. China University Teaching. 1, 9-13, 34

[5] Dong Rongsheng Gu Tianlong(2009), Computational Thinking and Methodology of Computer, J. Computer Science. 36, 1,1-4, 42

[6] Mou Qin Tan Liang (2011), Research and Evolvement of Computational Thinking, J. Computer Science. 38, 3, 10-15 